\section{Estudo \\ Ed Debate}

em Cestã⿻

Plamejamento
Revista Estudo \& Debate, Lajeado, v. 24, n. 1, 2017. ISSN 1983-036X

DOI: http://dx.doi.org/10.22410/issn.1983-036X.v24ila2017.1271

\title{
A EVASÃO UNIVERSITÁRIA: UMA ANÁLISE ALÉM DOS NÚMEROS
}

\author{
Nathália Prochnow Nagai ${ }^{1}$, André Luís Janzkovski Cardoso ${ }^{2}$
}

\begin{abstract}
Resumo: Nos últimos anos a evasão no ensino superior público no Brasil tem tomado grandes proporções e, consequentemente, tem sido alvo de diversos estudos. Assim, este trabalho buscou comparar as principais razóes que provocam a evasão dos cursos de administraçáo, ciências contábeis, ciências econômicas e sistemas de informação da UFMT - Campus Rondonópolis a partir de aspectos demográficos. Para esta pesquisa, optouse por abordagens qualitativa e quantitativa. A coleta de dados foi realizada por meio de entrevistas com os coordenadores dos cursos e questionário eletrônico enviado para os alunos. No tratamento de dados foram utilizados modelos estatísticos como a análise fatorial e o comparativo entre médias. Os resultados indicam que há diferenças estatisticamente significativas a um nível de significância de 0,05 entre as razóes de evasão e as variáveis demográficas gênero, estado civil, ensino médio e curso. Observa-se que não há diferenças estatisticamente significativas entre os semestres e as razóes de evasão. Os dados qualitativos indicaram algumas razões não observadas anteriormente. A evasáo de alunos na universidade caminha em direçáo oposta ao desenvolvimento, pois o potencial capital social, uma importante ferramenta que auxiliaria no progresso econômico e social, e no fortalecimento da democracia, pode acabar não sendo desenvolvido.
\end{abstract}

Palavras-chave: Educação. Ensino Superior. Evasão.

\section{UNIVERSITY DROPOUT: AN ANALYSIS BEYOND THE NUMBERS}

\begin{abstract}
In the past few years dropout in public higher education in Brazil has taken great proportions and, consequently, has been the subject of several studies. Therefore, this study sought to compare the main reasons that cause the dropout of administration, accountancy, economic sciences and information systems courses from UFMT - Rondonópolis through demographic aspects. For the research both a qualitative and quantitative approach were applied. Data was collected through interviews with the course coordinators with and electronic questionnaire sent to the students. For data treatment, statistical models including factor analysis and average comparatives were used. Finally, the results indicate that, there are statistically significant differences at a 0.05 significance level among the evasion reasons and demographic variables such as gender, marital status, high school and course. It was also observed that there are no statistically significant differences between the variable semesters and the dropout reasons. The qualitative data showed dropout reasons not observed previously. The university dropout moves in the opposite direction to from the development, as the potential social capital, an
\end{abstract}

1 Bacharel em Administração ICHS - CUR - UFMT. E-mail: nagainathalia@gmail.com

2 Professor Dr. em Administração ICHS - CUR - UFMT. E-mail: cardoso9778@gmail.com 
important tool that would assist in the economic and social progress and the strengthening of democracy, might end up not being developed.

Keywords: Education, Higher Education, Dropout.

\section{INTRODUÇÁO}

É a partir da década de 1990, com o estudo realizado pela Comissão Especial de Estudos Sobre Evasão, que este tema recebeu maior atenção no Brasil, impulsionando a realização de diversos estudos que procuraram evidenciar ou mesmo compreender os motivos que levam a tal fenômeno. Conforme noticiado no portal do Senado federal, segundo o MEC, cerca de $40 \%$ dos estudantes que entram nas universidades públicas abandonam o curso antes da conclusão (SENADO FEDERAL, 2014).

A ineficiência na retenção dos alunos no ensino superior público pode provocar significativo desperdício financeiro, uma vez que os recursos, ora investidos na instituiçáo de ensino, não geram o retorno esperado. Ademais, as consequências abrangem os âmbitos pessoal, econômico e social.

No âmbito pessoal tais consequências podem ser traduzidas em sentimentos de frustração, incapacidade intelectual, insegurança, medo e fracasso. Também podem afetar áreas na esfera psicológica, física, escolar e interpessoal do discente.

Em relação aos aspectos econômicos, o aluno que deixa o ensino superior encontra maiores dificuldades em entrar no mercado de trabalho, dessa forma causando impacto significativo no crescimento da economia e ampliando a desigualdade social. As universidades também enfrentam ineficiência no uso de seus orçamentos que acaba por refletir na própria sociedade.

Já no âmbito social, conforme Tinto (2004), as pessoas com ensino superior são mais propensas a contribuir efetivamente no desenvolvimento da sociedade, pois cooperam com serviços comunitários, utilizam menos serviços públicos e cometem menos crimes. À medida que menos pessoas estão se graduando, o capital social de determinada comunidade acaba se reduzindo.

A principal motivação para a realização desse estudo foi descobrir as razóes que levam os alunos de universidades federais a deixarem seus cursos. Diante dessas consideraçôes a respeito da evasão, este trabalho teve como objetivo comparar, a partir de aspectos demográficos, as principais razóes que provocam a evasão de alunos dos cursos de administração, ciências contábeis, ciências econômicas e sistemas de informação da Universidade Federal de Mato Grosso - UFMT - Campus Universitário de Rondonópolis entre os anos de 2010 a 2014. E como suporte, os objetivos específicos buscaram comparar as razões de evasão considerando: (1) gênero; (2) semestre; (3) estado civil; (4) ensino médio cursado; e (5) cursos.

A coleta de dados foi realizada em dois momentos diferentes por meio de entrevistas com os coordenadores dos cursos com um roteiro semiestruturado e questionário eletrônico enviado aos alunos. No tratamento de dados foram utilizados modelos estatísticos abrangendo análise fatorial, correlaçóes e comparativo entre médias e, a partir disso, os resultados são discutidos. 
Este trabalho contribui de forma teórica à medida que traz novas informaçóes a respeito das possíveis razóes de evasão na visão dos próprios evadidos e também dos coordenadores dos cursos em questáo. $\mathrm{O}$ estudo também vai além, buscando não apenas identificar as razóes, mas ainda analisar os antecedentes e consequentes da saída do aluno do ensino superior. A contribuição prática deste estudo consiste em informações valiosas tanto para os coordenadores de curso quanto para a pró-reitoria da universidade, para que possam iniciar açóes para a redução da evasão, já que são poucas as instituições que possuem programas de acompanhamento e combate à evasão.

\section{REFERENCIAL TEÓRICO}

O referencial teórico deste artigo está dividido em quatro partes, incluindo conceitos de evasão, os antecedentes e as consequências da evasão, estudos sobre o tema e algumas questóes sobre o capital social.

\subsection{A evasão e seus conceitos}

É importante ressaltar que o conceito de evasão em si pode variar de acordo com a instituição de ensino. Mello et al. (2012) adotaram a definição de evasão do Departamento de Registros Acadêmicos (DRA) do seu objeto de estudo, que por sua vez considera como evadido aquele aluno que ingressou na IES e que não solicitou matrícula em disciplinas por dois semestres consecutivos ou alunos que solicitam o cancelamento de matrícula junto ao DRA por meio de declaração.

Barroso (2004, p. 11) traz uma perspectiva diferente do termo evasão, definindo-a como "o processo de abandono de qualquer curso dentro da instituição". Ou seja, o aluno que faz outro vestibular (até mesmo para a mesma instituição) é considerado como aluno que abandona o curso, por outro lado, o aluno que realiza a transferência dentro da instituição não é definido como evadido.

Pereira (1996) caracteriza a evasão em três formas diferentes. A Evasão da Universidade acontece quando um aluno deixa a universidade sem concluir nenhum curso compreendendo o abandono, o cancelamento (próprio ou pela instituição) e a transferência. A chamada Evasão de Área ocorre caso o aluno tenha feito mobilidade dentro da mesma instituição, mas em uma área diferente de seu curso original, e a Evasão de Curso que ocorre quando o aluno migra para outro curso sendo este na mesma área ou não.

Para completar essa visão, a Comissão Especial de Estudos sobre Evasão (1996) também conceitua a evasão de três formas: Evasão de Curso, da Instituição e do Sistema. A Evasão de Curso é definida como a saída definitiva do aluno de seu curso de origem, sem concluí-lo. A Evasão da Instituição é aquela onde o aluno se desliga da instituição em que estava matriculado. E a Evasão do Sistema é representada pela saída de um aluno, definitiva ou temporária, do ensino superior.

Diante dos diversos tipos de evasão encontrados na literatura, a Evasão do Sistema foi o conceito adotado para a realizaçáo desta pesquisa, pois abrange a saída, definitiva ou temporária, de aluno do ensino superior considerando os cursos de administração, ciências contábeis, ciências econômicas e sistemas de informação. 


\subsection{Os antecedentes e as consequências}

Como se pode acompanhar por meio dos Censos Escolares disponibilizados pelo MEC/INEP, o número de alunos que estão ingressando em universidades federais aumenta a cada ano, contudo, ainda é pequeno o número de concluintes. Em 2013, este mesmo censo mostra a Universidade Federal de Mato Grosso com um número total de 18.007 matrículas em cursos presenciais e com apenas 2.070 conclusões na mesma modalidade. (BRASIL/ MEC/INEP, 2013)

Há diversos fatores que podem afetar e influenciar a decisão do aluno de deixar seu curso, conforme o estudo da Comissão Especial de Estudos sobre Evasão (1996), pode-se afirmar que a evasão se mostra sob três fatores distintos: fatores referentes a características individuais do estudante, fatores internos às instituiçôes e fatores externos às instituições.

Pode-se inferir que a decisão do aluno em evadir é tomada a partir da combinação de diversos fatores, tanto pessoais, escolares, institucionais, sociais ou econômicos. Ademais Mello et al. (2012) aborda em sua pesquisa outros fatores que podem influenciar tal decisão, sendo eles, fatores psicológicos, sociológicos, organizacionais e interacionais.

O principal modelo teórico de explicação da evasão surgiu nos Estados Unidos na década de 70 a partir da discussão teórico-conceitual abordada por Tinto. Nesta teoria, Tinto (1975) compara a evasão no ensino superior ao suicídio na esfera social fundamentado, principalmente, por Durkheim, ou seja, quando não há interação suficiente com a comunidade acadêmica ou quando não há certa harmonia entre os valores individuais e os da coletividade universitária. Assim, o indivíduo acaba não tendo uma integraçáo no sistema social acadêmico o que pode aumentar a probabilidade de uma evasão.

Tinto (1997) apresenta uma nova proposta de representação deste processo longitudinal, em que a experiência em sala de aula se torna mais evidente. Neste modelo revisado, Tinto (1997) mantém o background familiar, atributos individuais e escolaridade anterior do aluno como fatores que influenciam a sua decisão de evadir e traz também maior ênfase aos compromissos externos que ao longo do tempo também influenciam a decisão. Tinto (1997) também relaciona o nível de integração acadêmica e social ocorrida dentro da sala de aula com a qualidade do esforço estudantil e o nível de aprendizagem, que por fim resultará na renovação de seus compromissos iniciais que determinarão a evasão ou a permanência. $\mathrm{O}$ modelo está apresentado na Figura 1. 
Figura 1 - Modelo sobre a relação entre sala de aula, aprendizagem e permanência

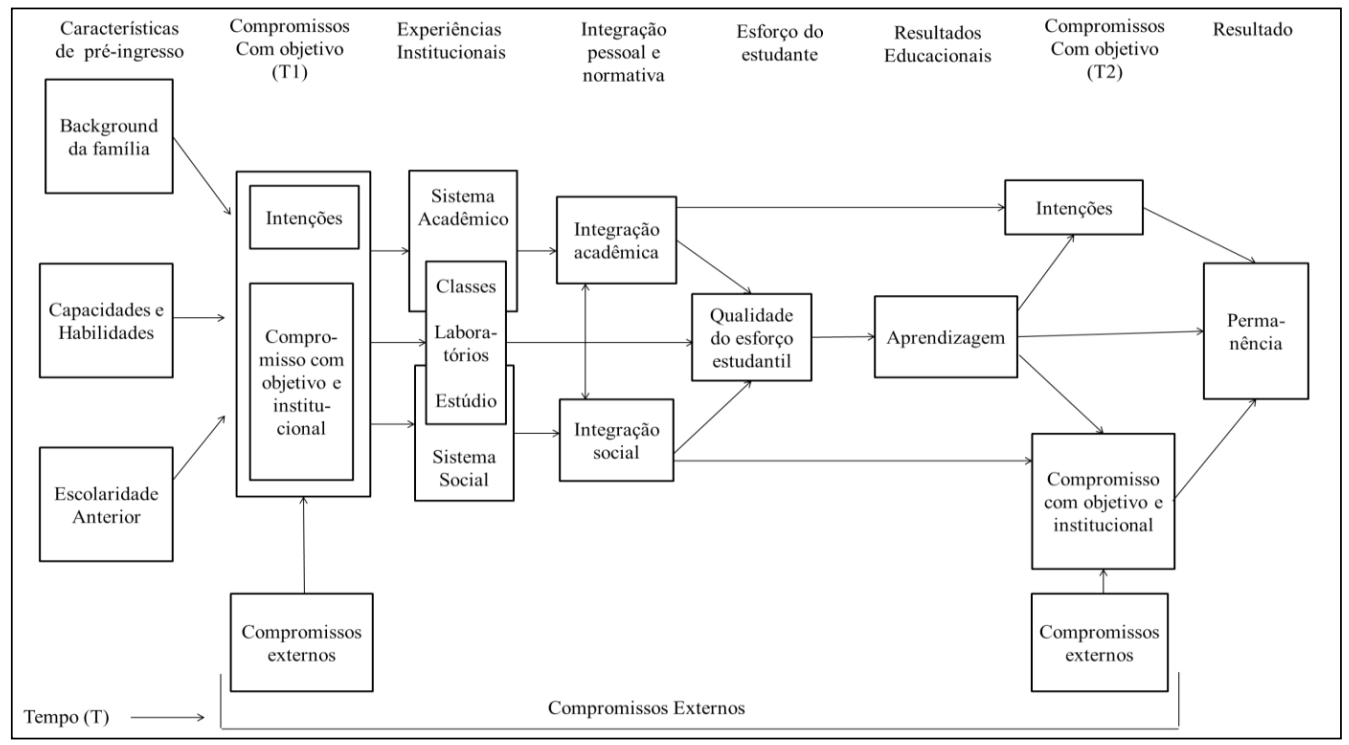

Fonte: Tinto (1997), adaptado pelos autores.

Assim, a partir do momento em que o aluno decide se desligar do ensino superior, ele está sujeito a diversas consequências. De acordo com Ataíde (2006) o grau de escolaridade constitui um dos principais fatores que determina o nível de empregabilidade, como o mercado cada vez mais demanda profissionais altamente qualificados, uma pessoa que não completa seu ensino superior pode encontrar maiores dificuldades em se empregar e, consequentemente, sofrer significativo impacto na sua vida financeira e social.

Também se deve levar em conta que os prejuízos podem variar de acordo com a subjetividade e prioridades de cada um, a não graduação de um aluno pode trazer à tona diversos sentimentos como desmotivação, desânimo, medo, insegurança, fracasso e por fim até um sentimento de incapacidade intelectual que posteriormente poderá ocasionar dificuldades profissionais e de autorrealização (BAGGI, 2010; FIALHO 2014).

Prestes (2014) aborda três diferentes tipos de perdas provocados pela evasão, sendo as perdas sociais, econômicas e o descumprimento da política gerencial da instituição. Os orçamentos anuais das universidades são calculados a partir do montante de alunos matriculados, porém, ao longo do tempo alguns alunos abandonam a instituição e não concluem o curso. Desta forma, universidades enfrentam ineficiência no uso de seus orçamentos, pois se planejam para atender um número maior de alunos, mas mantém a mesma estrutura para atender a um número reduzido de alunos, provocando prejuízos econômicos para a instituição que por sua vez são refletidos na sociedade.

A universidade falha em não conseguir realizar sua missão de formar pessoas que contribuam com a sociedade, o progresso e desenvolvimento da nação. Pois, conforme Tinto (2004) pessoas com uma educação superior são mais propensas a participar efetivamente no governo da nação, contribuindo com tempo e dinheiro para serviços comunitários, 
consumindo menos serviços públicos e cometendo menos crimes. Elas também contribuem para o crescimento econômico e produtividade.

Tinto (1975) também afirma que o aluno não é o único responsável pelo fracasso escolar, conforme ele discorre em seu modelo longitudinal de evasão, a universidade exerce grande influência na decisão do aluno em abandonar o ensino superior, pois suas expectativas podem não ter sido atendidas provocando uma grande insatisfação com a instituição. Dessa forma, as estratégias de retenção ou de minimização da evasão se fazem indispensáveis, lembrando que cada instituição deve identificar as causas do fenômeno em seu ambiente educacional.

\subsection{Estudos acerca da evasáo}

Os estudos envolvendo o tema evasão no ensino superior foram impulsionados no Brasil principalmente depois de um seminário acerca da evasão nas Universidades Brasileiras realizado em fevereiro de 1995 (ADACHI, 2009). A partir daí, em março daquele mesmo ano, foi criada a Comissão Especial de Estudos sobre Evasão que visava compreender com profundidade tal tema e, posteriormente, contribuir para que as Instituiçóes Federais de Ensino Superior reduzissem sua taxa de evasão.

O estudo trouxe um panorama geral da evasão em diversas universidades federais do país, e junto aos participantes e membros da pesquisa identificou três ordens de fatores diferentes que contribuem para a evasão, em primeiro lugar aqueles que se relacionam ao próprio estudante, os relacionados ao curso e à instituição e por fim os fatores socioculturais

e econômicos externos. Segundo a Comissão Especial de Estudos sobre Evasão (1996), os principais fatores relacionados a características individuais do estudante são:

- Situação socioeconômica

- Opção por mudança de curso ou de carreira

- Desencanto com o curso escolhido

- Pouco preparo para enfrentar o nível de dificuldade exigido por alguns cursos

- Desinformação do aluno quanto à carreira inicialmente escolhida

Os principais fatores de ordem institucional são:

- Grade curricular extensa, rígida, estratificada, conservadora e desatualizada

- Didática-pedagógica

- Insuficiente número de docentes

Já os fatores externos destacados são:

- Perspectiva de remuneração e a possibilidade de emprego

- Dificuldades profissionais vislumbradas

- Falta de base do aluno levando a reprovaçóes sucessivas

A pesquisa de Polydoro (2000), realizada em uma instituição particular do estado de São Paulo, traz uma abordagem diferente acerca da evasão. O objetivo foi analisar o trancamento de matrícula no que se refere às condiçóes envolvidas na saída e no retorno 
do estudante à instituição. Os principais motivos de abandono destacados foram: o suporte financeiro (situação econômica do aluno), condiçóes relacionadas a trabalho (interferência das questóes do trabalho na realização do estudo), a integração acadêmica (percepçáo do desempenho acadêmico, condiçóes pessoais de estudo, qualidade dos professores, relacionamento interpessoal e organização do curso) e o baixo comprometimento com o curso (segurança na escolha do curso e perspectiva de realização profissional).

Veloso (2002) retrata a evasão nos cursos de graduação da Universidade Federal do Mato Grosso, campus universitário de Cuiabá, assumindo uma abordagem qualitativa e quantitativa em que foi capaz de traçar o perfil do aluno evadido. A pesquisa revelou que a maioria dos evadidos é do gênero masculino na faixa etária dos 25 anos, e que os cursos com maior demanda apresentam menor evasão, foram identificados cinco fatores quanto à questáo da evasáo observados pelos coordenadores dos cursos, sendo eles: o aluno e sua contribuição, a estrutura física, a estrutura do curso, o mercado de trabalho e o docente. Os resultados obtidos na pesquisa de Veloso (2002) supóem que a evasão náo foi somente um processo dependente do aluno, tendo também um componente institucional, reflexo da ausência de uma política de permanência do aluno no curso de sua opçáo.

Alguns estudos trazem o fator econômico como um antecedente da evasão (BARROSO, 2004; BORGES, 2011, PEREIRA, 2003 e RIBEIRO, 2005). É interessante notar como o mesmo fator influencia tanto instituições particulares quanto instituiçóes federais e também como ele se faz presente no decorrer do tempo. O estudo de Barroso (2004), realizado no instituto de Física da Universidade Federal do Rio de Janeiro, traz ainda fatores inerentes à escolha inadequada do curso e da instituição, retrata que a evasão se dá nos dois primeiros anos de curso e geralmente está relacionada ao fracasso nas disciplinas iniciais.

O estudo de Mello et al. (2012) teve como objetivo revelar os fatores que contribuem para a evasão no curso superior de administração em uma universidade pública do sul do Brasil. Com o uso do método qualitativo os resultados revelaram que os homens evadem mais do que as mulheres, como também observado no estudo de Furtado (2012). Os fatores explicativos da evasão se apresentam como questôes relacionadas ao trabalho, também apontadas por Barcelos (2012) e expectativas diferentes em relaçâo ao curso. As possíveis açóes para diminuir a evasão apontadas pelos autores foram: melhoria na estrutura física das instituiçóes, melhor relação entre aluno, curso e docente e bolsas permanência.

O estudo de Adachi (2009) teve por objetivo analisar a evasão em cinco cursos da Universidade Federal de Minas Gerais e, por meio de análises quantitativa e qualitativa, mostra que a evasão é mais elevada em cursos que exigem notas mais baixas para entrada, em graduaçóes cujo perfil do discente é de nível socioeconômico e cultural, predominantemente, baixo. Porém, alunos de classificação socioeconômica mais baixa que recebem apoio da assistência estudantil apresentam altos índices de conclusão.

É possível indicar por meio da revisão da literatura que são diversos os fatores e o perfil do aluno que influenciam a evasão, alguns convergem em diversas instituiçóes outros são típicos de cada uma. É importante levar em conta que cada instituição tem características singulares e que, conforme Furtado (2012), as universidades devem adotar 
processos de gestão que sejam preventivos e corretivos quanto à evasão, reduzindo assim os índices de abandono.

A última parte do referencial teórico apresenta algumas questôes sobre o capital social.

\subsection{0 capital social}

Podem-se observar diversas discordâncias e consonâncias entre as concepçóes de capital social. De acordo com Bourdieu (1980), o capital social revela um conjunto de recursos e potenciais recursos resultantes do fato de pertencer por um significativo período de tempo, a redes de relações de conhecimento e reconhecimento mútuo. Sua ênfase está no tempo da relação dos atores e em seu potencial de desenvolvimento.

Já para Putnam (2006), um dos principais autores acerca da temática, o capital social se refere a aspectos da organização social, como redes, normas e confiança que facilitam a coordenação e cooperação em prol do benefício mútuo. $\mathrm{O}$ autor também discorre sobre dois tipos de capital social, o bonding e o bridging. O capital social bonding tende a reforçar a lealdade entre os membros de um determinado grupo, já o capital social bridging gera reciprocidade e identidade mais abrangentes, criando laços de conectividade entre diferentes grupos. A concepção de Putnam (2006) dá maior ênfase na dimensão política, de forma que a atuação cívica de uma sociedade possibilitaria prever o desenvolvimento de uma determinada região.

Como é o exemplo da Itália moderna descrita por Putnam (2006), há um grande contraste entre as regióes Norte e Sul e coincidentemente as regióes com melhor desempenho institucional (regiōes do Norte) também são as regiōes com maior participação cívica. Nessas regióes os cidadãos participam ativamente de todos os tipos de associaçóes locais, além de se envolverem na política. Assim, conforme o autor, quanto mais cívica a região mais eficaz é seu governo.

Não é somente para o desenvolvimento que o capital social traz contribuiçóes. Vários estudiosos retrataram como o capital social influencia no desempenho da democracia e no engajamento cívico efetivo (AMARAL, 2011; GOHN, 2004; WALTER et al., 2003). Putnam (2006) identifica que a organização social, sustentada por uma rede de associaçóes civis, pela cooperação baseada em normas compartilhadas e pela confiança mútua se fez fundamental para um bom desempenho da democracia, da sociedade e da economia em algumas regióes da Itália segundo estudo realizado em 1970.

Baquero (2003) descreve o capital social como um importante instrumento de empowerment dos cidadãos, onde há envolvimento dos indivíduos em atividades coletivas que geram benefícios ampliando as redes de cooperação. Assim, surtindo impacto positivo na democracia e no desenvolvimento econômico.

O desenvolvimento, tanto econômico quanto social, sempre foi amplamente discutido ao longo do tempo e, atualmente, o capital social tem ganhado espaço neste debate. Por integrar diferentes conceitos como reciprocidade, participação, governabilidade e não apenas os recursos financeiros e humanos, tal conceito contribui de forma mais ampla para a compreensão do desenvolvimento de regióes distintas, com características singulares. 
Um exemplo apresentado por Tabosa et al. (2004) inclui os estudos realizados pelo atual Instituto de Pesquisa e Estratégia do Ceará (IPECE) que demonstraram casos de núcleos e arranjos produtivos locais bem-sucedidos que, em sua maioria, apresentavam um significativo estoque de capital social. Inclui também casos malsucedidos em que, na maioria das vezes, foi verificada a ausência do capital social.

De acordo com Bilert et al. (2011), para a construçáo de um desenvolvimento sustentável e uma democracia saudável, caracterizada pela alta e comprometida participaçáo civil, é necessária uma efetiva interação entre o capital social, poder público e as demais instituiçóes envolvidas, além da atuação estruturada em redes, onde as açóes individuais estejam direcionadas para as ações coletivas.

Uma instituição de ensino superior não tem apenas como dever formar profissionais e força de trabalho qualificada, mas cidadãos. Em um ambiente acadêmico os alunos devem ser capazes de desenvolver um espírito crítico, a criatividade, a comunicação, a capacidade de gerar ideias e solução de problemas e compartilhar as mais diversas experiências. Devem ser desafiados a se desenvolver como cidadãos.

De acordo com Tonkaboni (2013) a partir da socialização acadêmica, valores, cultura e normas são compartilhados com os alunos, possibilitando o estabelecimento de laços e de novas redes que podem levar ao desenvolvimento do capital social. Dessa forma, as instituiçóes educacionais, e principalmente as instituiçóes de ensino superior, têm sido consideradas "produtoras poderosas" (TONKABONI, 2013, p. 44) de capital social, justamente por oferecer um ambiente propício para que essas relaçôes sociais aconteçam.

Desta maneira, o capital social é uma importante ferramenta que auxiliaria no desenvolvimento econômico e social, e no fortalecimento da democracia, com cidadáos mais bem informados, desempenhando papéis participativos e engajados. A evasão universitária reduz as possibilidades de ampliação do capital social e se mostra na direção oposta ao desenvolvimento da sociedade brasileira. Por isso, o estudo da evasão e a criação de estratégias para a retenção se tornam táo importante.

\section{PROCEDIMENTOS METODOLÓGICOS}

Neste estudo foram adotados os métodos qualitativos e quantitativos. O público alvo foi de alunos registrados entre os anos de 2010 a 2014 nos cursos de Administração, Ciências Contábeis, Ciências Econômicas e Sistemas de Informação, e que não estavam matriculados em dezembro de 2014, totalizando assim 877 pessoas. Os cursos foram escolhidos devido às afinidades entre si, já que são cursos relacionados às ciências empresariais.

$\mathrm{Na}$ primeira fase da pesquisa foram realizadas entrevistas individuais com os coordenadores dos cursos fazendo uso de um roteiro semiestruturado disposto de quatro perguntas principais para identificar possíveis razōes da evasão. Após a finalização das entrevistas, o questionário eletrônico passou a ser formulado baseado nos estudos de Gomes (1999); Mazzetto (2002); Ataíde (2006); Machado (2009); Borges (2011); Mello et al. (2012) e Mendonça (2012). Por meio de uma escala Likert de 11 pontos, os alunos deveriam sinalizar as razóes que influenciaram sua decisão em deixar o curso considerando 
29 assertivas. As possíveis razōes foram retiradas dos estudos anteriores e das entrevistas com coordenadores.

Depois de finalizado, o questionário foi incluído no software Qualtrics para a realização de um pré-teste, solicitando feedback sobre a compreensão das questóes e indicaçóes de melhorias. Após a análise do feedback feita pelos respondentes, a versão final do questionário foi criada. O questionário foi enviado a 877 alunos, porém cerca de $7 \%$ dos e-mails apresentaram falha no envio. A pesquisa foi encerrada um mês depois de seu lançamento, com 242 respostas completas, apresentando uma taxa de retorno de 29,5\%. Destas respostas, 58 respostas não foram consideradas na pesquisa, pois indicavam alunos que no ano de 2015 voltaram a estudar, o que resultou em 184 respostas válidas.

Para o tratamento dos dados foi utilizado o software SPSS 20 empregando a análise fatorial, correlaçôes e comparativo entre médias. De acordo com Field (2009, p. 553) a análise fatorial se apresenta como "uma técnica para identificar grupos ou agrupamentos de variáveis". Ainda conforme o autor, tal técnica tem três usos principais: entender a estrutura de um conjunto de variáveis, construir um questionário para medir uma variável subjacente e reduzir um conjunto de dados a um tamanho mais manejável. Para essa pesquisa foi considerado o uso da rotação varimax.

Por fim, com o objetivo de analisar com profundidade a relação entre as variáveis demográficas e as razóes de evasão, foram realizadas comparaçôes entre as médias, buscandose evidenciar diferenças estatisticamente significativas, considerando as seguintes hipóteses:

H1) Há diferenças entre as razões de evasão de acordo com o gênero;

H2) Há diferenças entre as razões de evasão e os semestres que deixam o curso;

H3) Há diferenças entre as razóes de evasão e o estado civil;

H4) Há diferenças entre as razões de evasão e o ensino médio cursado;

H5) Há diferenças entre as razões de evasão de acordo com o curso.

A Figura 2 apresenta as etapas seguidas para a realizaçáo da pesquisa. O processo para a caracterização da proposta de pesquisa, intercalou a definição de um problema de pesquisa, objetivos e hipóteses com diversas leituras sobre o tema, de maneira a refinar como a pesquisa se daria e quais os procedimentos metodológicos. A partir das entrevistas com os coordenadores dos cursos e, principalmente, da elaboraçáo do referencial teórico, o processo de coleta de dados por meio do questionário e a subsequente análise dos dados utilizando as técnicas estatísticas propiciaram a comparação com estudos anteriores, as discussōes e reflexões finais desta pesquisa. Considerando o que indica Hair Jr. et al. (2006), de que há a necessidade de se obter uma amostra mínima de cinco vezes o número de variáveis do questionário, as respostas às 29 assertivas requereriam um mínimo de 145 respondentes, e nesta pesquisa foram obtidas 184 respostas válidas, o que não indica a limitação para a generalização dos resultados para a população pesquisada.

Na sessão seguinte os dados são apresentados e se faz a discussão dos resultados. 
Figura 2 - Desenho da pesquisa



Fonte: os autores, 2016.

\section{APRESENTAÇÃO DOS DADOS E DISCUSSÁO DOS RESULTADOS}

Os dados serão discutidos a partir de análises quantitativas e qualitativas.

\subsection{Análises quantitativas}

Para a análise fatorial foi utilizado o método dos componentes principais que leva em conta a variação total dos dados. Após rodar a análise, as 29 assertivas anteriormente incorporadas em cinco grupos se redistribuíram em oito fatores principais que juntos explicaram $65,5 \%$ da variação total e apresentaram valores de $\mathrm{KMO}=0,747$. Os oito novos fatores apresentaram separadamente alfa Cronbach variando entre 0,563 e 0,867 e Alfa 0,800 quando calculados juntos. A Tabela 1 apresenta o resultado da análise fatorial das 29 assertivas e sua variância total explicada. 
Tabela 1 - Variância Total Explicada

\begin{tabular}{ccccccc}
\hline \multirow{2}{*}{ Fatores } & \multicolumn{3}{c}{ Carga dos Fatores sem Rotaçáo } & \multicolumn{3}{c}{ Carga dos Fatores com Rotaçáo } \\
\cline { 2 - 7 } & Total & $\begin{array}{c}\text { \% de } \\
\text { Variância }\end{array}$ & $\begin{array}{c}\text { \% de Variância } \\
\text { Acumulada }\end{array}$ & Total & $\begin{array}{c}\text { \% de } \\
\text { Variância }\end{array}$ & $\begin{array}{c}\text { \% de Variância } \\
\text { Acumulada }\end{array}$ \\
\hline 1 & 5,750 & 19,829 & 19,829 & 4,079 & 14,066 & 14,066 \\
2 & 2,986 & 10,296 & 30,125 & 2,959 & 10,202 & 24,268 \\
3 & 2,576 & 8,883 & 39,008 & 2,365 & 8,155 & 32,423 \\
4 & 2,276 & 7,849 & 46,857 & 2,346 & 8,089 & 40,512 \\
5 & 1,582 & 5,456 & 52,313 & 2,057 & 7,093 & 47,605 \\
6 & 1,387 & 4,783 & 57,096 & 1,872 & 6,454 & 54,059 \\
7 & 1,330 & 4,585 & 61,681 & 1,659 & 5,720 & 59,779 \\
8 & 1,099 & 3,788 & 65,469 & 1,650 & 5,690 & 65,469 \\
\hline
\end{tabular}

Fonte: os autores, 2016.

Como foram descobertos novos fatores e outros se agruparam de maneira diferente, excluindo ou incluindo assertivas, foi necessária uma readequação na nomenclatura dos fatores antes dispostos, conforme apresentado no Quadro 1.

A partir da análise foi possível identificar que os fatores Estrutura do Curso, Estrutura da Instituição, Pessoal, Mercado de trabalho que anteriormente estavam agrupados, foram divididos em fatores singulares. Também surgiram fatores novos não percebidos anteriormente, como é o caso dos fatores Escolha do Curso, Cidade, Conciliar Estudo e Trabalho e Aprendizado.

A redução dos dados de 29 assertivas em 8 fatores, e tendo em vista os parâmetros de qualidade e confiabilidade dos dados ora apresentados, propicia as análises subsequentes a fim de testar as hipóteses de pesquisa, atender aos objetivos específicos e responder ao problema de pesquisa deste estudo.

Quadro 1 - Fatores influenciadores da Evasão

\begin{tabular}{|c|c|c|}
\hline Fatores & Assertivas & Alfa Cronbach \\
\hline \multirow{6}{*}{ Estrutura do Curso } & Relacionamento entre aluno e professor & \multirow{6}{*}{0,867} \\
\hline & Método de professores & \\
\hline & Qualidade dos Professores & \\
\hline & Estrutura curricular & \\
\hline & Relacionamento entre aluno e aluno & \\
\hline & Prestígio do curso na cidade & \\
\hline \multirow{4}{*}{ Escolha do Curso } & Escolha inadequada do curso & \multirow{4}{*}{0,763} \\
\hline & Descobri que não tinha vocação para o curso & \\
\hline & Falta de conhecimento sobre o curso escolhido & \\
\hline & Mudança de Curso & \\
\hline
\end{tabular}




\begin{tabular}{|c|c|c|}
\hline Fatores & Assertivas & Alfa Cronbach \\
\hline \multirow{3}{*}{ Cidade } & Dificuldades em se manter em uma nova cidade & \multirow{3}{*}{0,723} \\
\hline & Dificuldades em adaptar-se em uma nova cidade & \\
\hline & Mudança de cidade & \\
\hline \multirow{4}{*}{$\begin{array}{c}\text { Conciliar estudo e } \\
\text { trabalho }\end{array}$} & Dificuldade em conciliar estudo com trabalho & \multirow{4}{*}{0,646} \\
\hline & Dificuldade em se manter somente estudando & \\
\hline & Localização da Instituição & \\
\hline & Sobrecarga de atividades & \\
\hline \multirow{3}{*}{$\begin{array}{l}\text { Estrutura da } \\
\text { Instituição }\end{array}$} & Falta de material bibliográfico & \multirow{3}{*}{0,663} \\
\hline & Instalações inadequadas & \\
\hline & Greve & \\
\hline \multirow{4}{*}{ Pessoal } & Gravidez & \multirow{4}{*}{0,563} \\
\hline & Para cuidar de Filhos & \\
\hline & Doença & \\
\hline & Casamento & \\
\hline \multirow{3}{*}{ Mercado de Trabalho } & Oferta de emprego ou promoção & \multirow{3}{*}{0,596} \\
\hline & Pouca opção de emprego & \\
\hline & Expectativa de baixa remuneração após concluir o curso & \\
\hline \multirow{2}{*}{ Aprendizado } & Acúmulo de reprovaçôes & \multirow{2}{*}{0,679} \\
\hline & Dificuldades de aprendizado & \\
\hline
\end{tabular}

Fonte: os autores, 2016.

A partir da redistribuição dos fatores foram realizados os testes de normalidade e homogeneidade para a identificação de qual tipo de testes (paramétricos ou não paramétricos) devem ser utilizados para análise. Os resultados indicaram não haver normalidade da distribuição dos dados e não haver homogeneidade da variância dos fatores. Dessa forma, foram realizados os comparativos de média usando o teste de Mann-Whitney e o teste de Kruskal-Walis para verificar as hipóteses lançadas anteriormente sobre motivos de evasão e as variáveis demográficas.

\section{H1) Há diferenças entre as razóes de evasão de acordo com o gênero;}

Considerando um nível de significância de 0,05 é possível observar que há diferenças estatisticamente significativas entre os gêneros para os fatores Cidade e Aprendizado. Tal resultado segue representado na Tabela 2 . 
Tabela 2 - Comparações entre os gêneros - Teste Mann-Whitney

\begin{tabular}{lrrrrrrrr}
\hline & $\begin{array}{c}\text { Estrutura } \\
\text { do Curso }\end{array}$ & $\begin{array}{c}\text { Escolha } \\
\text { do } \\
\text { Curso }\end{array}$ & Cidade & $\begin{array}{c}\text { Conciliar } \\
\text { estudo e } \\
\text { trabalho }\end{array}$ & $\begin{array}{c}\text { Estrutura } \\
\text { da } \\
\text { Instituiçáo }\end{array}$ & $\begin{array}{c}\text { Pessoal } \\
\text { Mercado } \\
\text { de } \\
\text { Trabalho }\end{array}$ & Aprendizado \\
\hline Mann-Whitney U & 3310,0 & 3504,0 & 3044,0 & 3367,0 & 3267,0 & 3269,0 & 3733,0 & 3050,0 \\
\hline Z & $-1,614$ & $-1,053$ & $-2,385$ & $-1,449$ & $-1,739$ & $-1,733$ &,- 389 & $-2,367$ \\
\hline $\begin{array}{l}\text { Asymp. Sig. } \\
\text { (2-tailed) }\end{array}$ &, 106 &, 293 &, 017 &, 147 &, 082 &, 083 &, 697 &, 018 \\
\hline
\end{tabular}

Fonte: os autores, 2016.

A maioria dos estudos não identifica se há diferenças nas percepções de acordo com o gênero, as pesquisas apenas apresentam o número de evadidos, que em sua maioria são homens, conforme identificado no estudo de Mello et al. (2012).

Essas diferenças entre as percepçóes podem ser explicadas de acordo com a subjetividade, prioridades e experiências de cada pessoa. Conforme observado anteriormente no referencial teórico (TINTO 1997), os antecedentes da evasão estão relacionados a características de pré-ingresso, aos compromissos externos, ao compromisso com o objetivo de se graduar, a integração pessoal e acadêmica e também ao esforço do estudante. Desta maneira, as razóes que provocam a evasão estão sujeitas a mudar de pessoa para pessoa.

Por fim, a hipótese 1 (H1) foi confirmada, ou seja, há diferenças estatisticamente significativas entre as razóes de evasão de acordo com o gênero.

\section{H2) Há diferenças entre as razóes de evasáo e os semestres em que os alunos deixam o curso;}

Conforme apresentado na Tabela 3, observa-se que não há diferenças estatisticamente significativas (a um nível de significância de 0,05) entre os semestres e os fatores influenciadores da evasão.

Tabela 3 - Comparações entre os semestres - Teste Kruskal-Walis

\begin{tabular}{lrrrrrrrr}
\hline & $\begin{array}{c}\text { Estrutura } \\
\text { do Curso }\end{array}$ & $\begin{array}{c}\text { Escolha } \\
\text { do Curso }\end{array}$ & Cidade & $\begin{array}{c}\text { Conciliar } \\
\text { estudo } \\
\text { trabalho }\end{array}$ & $\begin{array}{c}\text { Estrutura } \\
\text { da } \\
\text { Instituiçáa }\end{array}$ & Pessoal & $\begin{array}{c}\text { Mercado } \\
\text { de } \\
\text { Trabalho }\end{array}$ & Aprendizado \\
\hline Chi-Square & 8,755 & 10,248 & 11,075 & 4,474 & 6,060 & 5,915 & 13,778 & 1,024 \\
\hline Df & 7 & 7 & 7 & 7 & 7 & 7 & 7 & 7 \\
\hline Asymp. Sig. &, 271 &, 175 &, 135 &, 724 &, 533 &, 550 &, 055 &, 994 \\
\hline
\end{tabular}

Fonte: os autores, 2016.

De acordo com Veloso (2002), o baixo desempenho no ensino médio reflete no baixo desempenho das primeiras disciplinas do curso superior, resultando no abandono nos primeiros semestres. O resultado nesta análise indica que não há diferença entre os semestres e o fator aprendizado que inclui as assertivas em relação a dificuldades de desempenho, 
sendo assim este fator pode ter influenciado a evasão tanto nos primeiros como nos últimos semestres.

Assim, a hipótese 2 (H2) não foi corroborada, pois a análise não identificou diferenças estatisticamente significativas entre as razóes de evasão e os semestres em que os alunos deixaram o curso.

\section{H3) Há diferenças entre as razóes de evasão e o estado civil;}

A Tabela 4 apresenta as comparações entre Estado Civil. Foi possível observar diferenças estatisticamente significativas a um nível de significância de 0,05 entre os Casados e Solteiros em relação aos fatores Escolha do Curso, Conciliar Estudo e Trabalho e Estrutura da Instituição.

Tabela 4 - Comparaçóes entre Estado Civil - Teste Mann-Whitney

\begin{tabular}{|l|c|c|c|c|c|}
\hline \multirow{2}{*}{ Fatores } & (I) Estado Civil & (J) Estado Civil & Mann-Whitney U & Z & Sig. \\
\hline Escolha do Curso & Casado & Solteiro & 2493 & $-2,635$ & 0,008 \\
\hline \multirow{2}{*}{ Conciliar estudo e trabalho } & Casado & Solteiro & 2137 & $-3,792$ & 0,000 \\
\cline { 2 - 6 } & Solteiro & Divorciado & 19 & $-2,614$ & 0,009 \\
\hline Estrutura da Instituição & Casado & Solteiro & 2463 & $-2,733$ & 0,006 \\
\hline
\end{tabular}

Fonte: os autores, 2016.

Também foi possível observar diferenças de percepções entre os Solteiros e Divorciados no fator Conciliar Estudo e Trabalho.

Furtado (2012) indica que alunos casados ou divorciados apresentam maior probabilidade de deixarem seus cursos, devido a compromissos externos que podem ter um peso maior, afetando o compromisso em se graduar. Esses alunos podem ter a responsabilidade de sustentar a família e, por isso, enquanto estudam muitas vezes também trabalham. A dificuldade em conciliar as duas atividades pode acabar levando à evasão.

A hipótese 3 (H3) foi então corroborada, indicando que há diferenças estatisticamente significativas entre as razóes de evasão e o estado civil.

\section{H4) Há diferenças entre as razóes de evasão de acordo com o ensino médio cursado;}

Conforme a Tabela 5 apresenta, foi possível observar diferenças estatisticamente significativas entre a variável Ensino Médio e o fator Aprendizado. 
Tabela 5 - Comparaçôes entre Ensino Médio - Teste Mann-Whitney

\begin{tabular}{|c|c|c|c|c|c|c|c|c|}
\hline & $\begin{array}{l}\text { Estrutura } \\
\text { do Curso }\end{array}$ & $\begin{array}{l}\text { Escolha } \\
\text { do Curso }\end{array}$ & Cidade & $\begin{array}{l}\text { Conciliar } \\
\text { estudo e } \\
\text { trabalho }\end{array}$ & $\begin{array}{c}\text { Estrutura } \\
\text { da } \\
\text { Instituição }\end{array}$ & Pessoal & $\begin{array}{l}\text { Mercado de } \\
\text { Trabalho }\end{array}$ & Aprendizado \\
\hline $\begin{array}{l}\text { Mann- } \\
\text { Whitney } \\
\text { U }\end{array}$ & 1785,500 & 1832,500 & 2034,500 & 2031,500 & 1573,500 & 1942,500 & 1819,500 & 1318,500 \\
\hline $\begin{array}{l}\text { Wilcoxon } \\
\text { W }\end{array}$ & 14188,500 & 2183,500 & 2385,500 & 2382,500 & 13976,500 & 14345,500 & 14222,500 & 13721,500 \\
\hline $\mathrm{Z}$ & $-1,021$ &,- 833 &,- 026 &,- 038 & $-1,869$ &,- 394 &,- 885 & $-2,888$ \\
\hline $\begin{array}{l}\text { Asymp. } \\
\text { Sig. } \\
\text { (2-tailed) }\end{array}$ & ,307 & , 405 & ,979 & ,970 & ,062 & ,694 & ,376 & ,004 \\
\hline
\end{tabular}

Fonte: os autores, 2016.

Assim, há diferença na percepção do fator Aprendizado como influenciador da evasão entre respondentes vindos de escolas públicas e respondentes que concluíram o ensino médio em escolas privadas.

O ensino médio público muitas vezes deficiente pode explicar a diferença encontrada entre o fator Ensino Médio e o fator Aprendizado. Conforme Tinto (1997), a escolaridade anterior implica na relação entre sala de aula, aprendizagem e permanência. Assim, o aluno pode acabar tendo dificuldades em se integrar ao ambiente acadêmico e por fim, as dificuldades de aprendizado e inúmeras reprovações podem levar à evasão.

A hipótese 4 (H4) foi corroborada, sendo assim, há diferenças estatisticamente significativas entre as razóes de evasão de acordo com o ensino médio cursado.

\section{H5) Há diferenças entre as razóes de evasão de acordo com o curso.}

Quando os cursos são comparados entre si por meio do Teste Mann-Whitney, é possível observar que há diferenças estatisticamente significativas entre os cursos de Administração e Ciências Econômicas e entre os cursos de Ciências Contábeis e Ciências Econômicas em relação ao fator Estrutura do Curso.

Em relação ao fator Cidade, os cursos de Administração e Ciências Contábeis e Ciências Contábeis e Ciências Econômicas apresentaram diferenças estatisticamente significativas a um nível de significância de 0,05 .

Comparando os cursos de Administração e Ciências Econômicas, Administração e Sistemas de Informação e também os cursos de Ciências Contábeis e Sistemas de Informação foi possível observar uma diferença estatisticamente significativa entre os cursos em relação ao fator Aprendizado. Os resultados da Tabela 6 indicam que os alunos dos cursos apresentam diferentes percepções em relação a alguns fatores influenciadores da evasão. 
Tabela 6 - Comparaçóes entre Cursos - Teste Mann-Whitney

\begin{tabular}{|l|c|c|c|c|c|}
\hline \multirow{2}{*}{ Fatores } & (I) Curso & (J) Curso & Mann-Whitney U & Z & Sig. \\
\hline \multirow{2}{*}{ Estrutura do Curso } & Administração & Ciências Econômicas & 1296 & $-2,371$ & 0,018 \\
\cline { 2 - 6 } & Ciências Contábeis & Ciências Econômicas & 639 & $-3,116$ & 0,002 \\
\hline \multirow{2}{*}{ Cidade } & Administração & Ciências Contábeis & 858,5 & $-2,087$ & 0,037 \\
\cline { 2 - 6 } & Ciências Contábeis & Ciências Econômicas & 759 & $-2,174$ & 0,030 \\
\hline \multirow{3}{*}{ Aprendizado } & \multirow{2}{*}{ Administração } & Ciências Econômicas & 1329 & $-2,193$ & 0,028 \\
\cline { 2 - 6 } & & Sistemas de Informação & 608 & $-2,479$ & 0,013 \\
\cline { 2 - 6 } & Ciências Contábeis & Sistemas de Informação & 382,5 & $-1,99$ & 0,047 \\
\hline
\end{tabular}

Fonte: os autores, 2016.

Cada curso possui características singulares, os alunos que ingressam são diferentes, os professores e seus métodos, a estrutura curricular também difere de um curso para outro. Um curso pode receber um maior número de pessoas de fora da cidade, outro pode ter alunos ingressantes de um ensino médio deficiente, outro ainda pode enfrentar problemas de estrutura por falta de professores ou por ser um curso novo na instituição.

São essas características que podem justificar as diferenças encontradas entre os cursos. Sendo assim, a hipótese 5 (H5) de que há diferenças estatisticamente significativas entre as razóes de evasão de acordo com o curso foi corroborada.

Após a apresentação e discussão dos dados em termos quantitativos, passa-se a uma análise qualitativa realizada a partir das questóes abertas também incluídas no questionário enviado aos alunos.

\subsection{Análises qualitativas}

A Tabela 7 apresenta detalhadamente os dados demográficos dos respondentes da pesquisa. De todos os 184 respondentes, 65 são mulheres e 119 são homens com idade média de 26 anos (desvio padrão de 7,156). Em relaçáo ao estado civil, a maioria dos respondentes é solteira, totalizando 112 . Os respondentes que cursaram o ensino médio em instituição pública totalizaram 157, enquanto os que cursam em instituição particular totalizaram 27. 
Tabela 7 - Dados demográficos dos respondentes

\begin{tabular}{c|c|c|c|c|c|c|c|c|c}
\hline Curso & \multicolumn{2}{|c|}{ Gênero } & \multicolumn{2}{c|}{ Idade } & \multicolumn{3}{c|}{ Estado Civil } & \multicolumn{2}{c}{ Ensino Médio } \\
\hline & Feminino & Masculino & Média & $\begin{array}{c}\text { Desv. } \\
\text { Padrão }\end{array}$ & Solteiro & Casado & Outro & Público & Particular \\
\hline Administraçáo & 28 & 34 & 26,5 & 6,515 & 38 & 23 & 1 & 49 & 13 \\
\hline $\begin{array}{c}\text { Ciências } \\
\text { Contábeis }\end{array}$ & 14 & 23 & 24,1 & 4,822 & 26 & 8 & 3 & 31 & 6 \\
\hline $\begin{array}{c}\text { Ciências } \\
\text { Econômicas }\end{array}$ & 18 & 38 & 26,8 & 8,657 & 32 & 20 & 4 & 50 & 6 \\
\hline $\begin{array}{c}\text { Sistemas de } \\
\text { Informaçáo }\end{array}$ & 5 & 24 & 27,6 & 7,514 & 16 & 8 & 5 & 27 & 2 \\
\hline Total & 65 & 119 & 26,25 & 7,156 & 112 & 59 & 13 & 157 & 27 \\
\hline
\end{tabular}

Fonte: os autores, 2016.

Para enriquecer o trabalho e ir além dos números, o questionário enviado aos alunos evadidos disponibilizava um espaço onde os respondentes poderiam expressar suas opinióes ou deixar algum comentário. Além disso, com as questóes finais também foi possível identificar a situação atual dos alunos. Complementarmente, foram analisadas as respostas das questóes abertas buscando evidenciar as descobertas da análise quantitativa. Foram evidenciados exemplos de cada um dos fatores de evasão, além de problemas relacionados a pressão psicológica por parte de professores, despreparo de outros alunos, falta de linhas de pesquisa, projetos de extensão e iniciação científica, falta de professores, o fato do curso ser novo e também a didática em sala de aula.

A didática também foi mencionada como ultrapassada e até citada como "estilo militar" em um dos comentários. Outros pontos ressaltados pelos respondentes foram a falta de interação entre departamento e aluno e a falta de motivação por parte dos professores. Por outro lado, diversos respondentes elogiaram tanto a instituiçáo quanto os cursos e diversos alunos expressaram sua vontade de voltar a estudar.

As respostas das alunas foram quanto ao excesso de atividades que dificultaram a conciliação estudo e trabalho; questôes pessoais como a doença do pai, Esposo não apoiar, ter ficado viúva e pelo fim de um casamento conturbado, além da falta de compreensão de alguns professores, mudança de curso, mudança de cidade, condiçóes financeiras e ausência de moradia e dificuldade de acompanhar as disciplinas e não aproveitamento de disciplinas.

As respostas dos alunos foram pautadas em problemas com professores e alunos, excesso de atividades extra sala, falta de tempo para estudar, muitas reprovaçóes, falta de professores para as disciplinas, por achar que o curso náo prepara para o mercado, pelo curso ser novo, mudança de curso, mudança de cidade, localização do campus e distância de Rondonópolis a grandes centros, não conseguir emprego nem bolsas auxílio, não conseguir transferência para o noturno, falta de recursos para moradia, alimentação e locomoção, além de falta de alojamento.

Em relação a situação atual dos evadidos, dos 184 respondentes, $41 \%$ somente trabalham, $43 \%$ estudam e trabalham (período integral ou meio período), 13\% somente estudam e 3\% nem estudam e nem trabalham. Dos que estudam, a grande maioria está em instituiçóes particulares. 
De uma forma geral, os dados qualitativos reforçam as descobertas obtidas na análise quantitativa. $\mathrm{O}$ que permite que se passe para as consideraçóes finais desta pesquisa.

\section{CONSIDERAÇÓES FINAIS}

Os resultados das análises fatoriais deste estudo trouxeram oitos fatores relacionados à evasão. Alguns fatores foram encontrados na literatura existente como se pôde observar nos estudos da Comissão Especial de Estudos Sobre Evasão (1996), Gomes (1999), Polydoro (2000), Veloso (2002) e Mello et al. (2012). Já outros fatores, como Aprendizado, Pessoal e Cidade são novas reorganizaçóes trazidas por esta pesquisa.

A ausência do fator Financeiro isoladamente também foi uma questão intrigante na pesquisa. Polydoro (2000), Pereira (2003), Barroso (2004) e Borges (2011) anteriormente trouxeram a questão financeira como um fator singular. Já na presente pesquisa, as assertivas relacionadas a finanças se incorporaram em outros fatores.

Apenas a hipótese 2 de que há diferenças entre as razóes de evasão e os semestres em que os alunos deixam o curso não foi verificada. Ou seja, as percepçôes dos alunos não variam de acordo com a variação do semestre. É interessante observar que conforme apresenta Veloso (2002), principalmente nos primeiros semestres as questôes relacionadas ao aprendizado são motivadoras da evasão. Já neste estudo, não houve diferença estatisticamente significativa entre os semestres e o fator Aprendizado nem quanto aos demais fatores.

$\mathrm{O}$ estudo demonstrou entre as razões que provocam evasão, fatores relacionados ao curso e à instituição de ensino, e que a evasão não é só um processo dependente "apenas" do aluno (VELOSO, 2002), mas é também um fenômeno institucional, reflexo da ausência de uma política de permanência do aluno no curso de sua opçáo.

A pesquisa em questáo foi realizada entre os anos de 2010 a 2014 e do total de alunos, 260 eram do curso de administração, 224 do curso de ciências econômicas, 222 do curso de ciências contábeis e 171 do curso de sistemas de informação. Sendo assim, 877 alunos foram considerados evadidos somente nesses quatro cursos, uma expressiva parte de potenciais profissionais que deixam de se qualificar.

Os impactos da evasão envolvem o evadido, afetando seu nível de empregabilidade e desenvolvendo sentimentos de fracasso e até incapacidade intelectual, a instituição, que falha em cumprir seu papel de formar pessoas que contribuam com a sociedade. E também a sociedade, que acaba perdendo grande parte de seu potencial capital social.

Conforme mencionado anteriormente por Prestes (2014), os orçamentos anuais das universidades são calculados a partir do montante de alunos matriculados, porém, ao longo do tempo alguns alunos abandonam a instituição e não concluem o curso o que à ineficiência do gasto público. Contudo, a maior perda esteja justamente na redução da possibilidade de desenvolver cidadão que possam contribuir na geração de capital social para a sociedade.

Como indicado no referencial teórico, o capital social é uma grande ferramenta que contribui para o alcance do desenvolvimento de uma determinada região (TABOSA et al., 2004) e as instituições de ensino superior são poderosas produtoras de capital 
social (TONKABONI, 2013), já que oferecem um ambiente propício para que diversas interaçôes e relaçôes sociais aconteçam. Assim, a evasão ou a não continuidade de alunos na universidade caminha em direção oposta ao desenvolvimento e a criaçáo de capital social.

Desta forma, comparar as principais razóes que provocam a evasão dos cursos de administração, ciências contábeis, ciências econômicas e sistemas de informação da UFMT - Rondonópolis a partir de aspectos demográficos pode ter uma dupla contribuição. A primeira é uma contribuição teórica e metodológica, apresentando e discutindo os resultados, além dos números, trazendo os antecedentes, consequentes e as diferentes percepçóes de acordo com os aspectos demográficos, modelagem pouco explorada na literatura. A segunda é uma contribuição prática, pois este estudo apresenta informaçóes valiosas tanto para os coordenadores de cursos quanto para a pró-reitoria da universidade, que podem se valer desses dados para tomar medidas para edificar o sistema de ensino de modo a reduzir a evasão.

Como sugestóes de estudos futuros, indica-se ampliar a pesquisa aos demais cursos da UFMT- Campus Rondonópolis, para que seja possível identificar a situação de todos os cursos da instituiçãa com o objetivo de encontrar e traçar estratégias amplas de melhoria.

\section{REFERÊNCIAS}

ADACHI, A. A. C. T. Evasáo e evadidos nos cursos de graduação da Universidade Federal de Minas Gerais. Belo Horizonte, 2009. 214 f. Dissertação - Mestrado em Educação, UFMG/FaE.

AMARAL, S. A. T.; RI, L. D. Capital Social, Democracia e Desenvolvimento. Perspectivas em Gestão \& Conhecimento, João Pessoa, v. 1, n. 2, p. 136-149, jul./dez. 2011.

ATAIIDE, J. S. P.; LIMA, L. M.; ALVES, E. de O. A repetência e o abandono escolar no curso de licenciatura em física: um estudo de caso. Revista Physicae. v. 6, 2006.

BAGGI, C. A. dos S.; LOPES, D. A. Evasão e Avaliação Institucional no Ensino Superior: uma discussão bibliográfica. Avaliação, v. 16, n. 2, p. 355-374, jul. 2011.

BAQUERO, M. Construindo Uma Outra Sociedade: O Capital Social na Estruturação de Uma Cultura Política Participativa No Brasil. Rev. Sociol. Polít., Curitiba, 21, p. 83108, nov. 2003.

BARCELOS, H. C.; RAIMANN, E. Análise evasão e reprovação universitária: uma análise a partir dos alunos do curso de sistemas de informação do IFG. 6o Seminário de Iniciação Científica, Goiânia, 2012.

BARROSO, M. F.; FALCÃO, E. B. M. EVASÃO UNIVERSITÁRIA: O CASO DO INSTITUTO DE FÍSICA DA UFRJ. IX Encontro Nacional De Pesquisa Em Ensino De Física. Jaboticatubas, 2004. 
BILERT, V. S. de S.; PERONDI, M. A.; PEREIRA, A. A.; TERNOSKI, S. A

Contribuição do Capital Social Para o Desenvolvimento Local Sustentável. Ciências Sociais Aplicadas em Revista - UNIOESTE/MCR - v. 11 - n. 21 - 2o sem. 2011 - p. 2942.

BOURDIEU, P. Le capital social. In: Actes de la recherche en sciences sociales. Vol. 31, janvier 1980. Le capital social. pp. 2-3.

BORGES, S. M. Fatores determinantes da evasão escolar no ensino superior: o estudo de caso do ILES/ULBRA de Itumbiara. Goiânia, 2011. 77 f. Dissertação (mestrado), Programa de Pós-Graduação Stricto Sensu. Mestrado Profissional em Desenvolvimento Regional, Faculdades Alves Faria.

BRASIL, Ministério da Educação. Instituto Nacional de Estudos e Pesquisas Educacionais. Sinopse do ensino superior. Censos de ensino superior. 2013. Disponível em: <http://www.inep.gov.br>. Acesso em: 20 de abril. 2015.

COMISSÃO ESPECIAL DE ESTUDOS SOBRE EVASÃO (MEC/ANDIFES / ABRUEM/ SESU). Diplomação, retençáo e evasão nos cursos de graduaçáo em instituiçóes de ensino superior públicas. Brasília, 1996.

FIALHO, M. G. D.; PRESTES, E. M. Da T. Evasáo escolar no curso de pedagogia da UFPB: na compreensão dos gestores educacionais. MPGOA, João Pessoa, v.3, n.1, p. 4263, 2014.

FIELD, A. Descobrindo a estatística usando o SPSS. 2a ed. Porto Alegre. Artmed, 2009.

FURTADO, V. V. A.; ALVES, T. W. Fatores determinantes da evasão universitária: uma análise com alunos da UNISINOS. Contextus. Revista Contemporânea de Economia e Gestão. Vol. 10 - No 2 - jul/dez 2012.

GOHN, M. da G. Empoderamento e participação da comunidade em políticas sociais. Saúde e Sociedade v.13, n.2, p.20-31, maio-ago 2004.

GOMES, A. A. Evasão e Evadidos: O discurso dos alunos sobre evasão escolar nos cursos de licenciatura. Nuances. Vol. V - jul 1999.

HAIR JR.. F.; ANDERSON, R. E.; TATHAM, R. C.; BLACK, W. C. M. Análise Multivariada de dados. Porto Alegre: Bookman, 2006.

MACHADO, M. R. A evasão nos cursos de agropecuária e informática / nível técnico da Escola Agrotécnica Federal de Inconfidentes - MG (2002-2006). Brasília, 2009. 136 f. Dissertação (Mestrado em Educação), Universidade de Brasília. 
MAZZETTO, S. E.; CARNEIRO, C. C. B. e S.; Licenciatura em Química da Ufc: Perfil Sócio-Econômico, Evasão e Desempenho dos Alunos. Quim. Nova, Vol. 25, No. 6B, 1204-1210, 2002

MELLO, S. P. T. de; SANTOS, E. G. dos; SOARES, A. C.; REZENDE; A. M. C. A evasáo no curso de administraçáo: diagnostico e possibilidades em uma Universidade pública no sul do brasil. XXIII ENANGRAD. Bento Gonçalves, 2012.

MENDONÇA, C. M. C. de; SOUZA, T.; CAMPOS, D. F.; NÓBREGA, K. C. Análise Da Importância, Desempenho e Influência de Serviços na Retenção de Alunos em Curso de Administraçáo. Revista Gestão e Planejamento, Salvador, v. 13, n. 2, p. 294314, maio/ago. 2012.

PEREIRA, F. C. B. Determinantes da evasáo de alunos e os custos ocultos para as Instituiçóes de Ensino Superior. Florianópolis, 2003. 172 f. Tese (Doutorado) Engenharia de Produção - Universidade Federal de Santa Catarina.

PEREIRA, J. T. V. Uma contribuição para o entendimento da evasão. Um estudo de caso: Unicamp. Revista da avaliação da educação superior, v. 1, n. 2. São Paulo, 1996.

POLYDORO, S. A. J. O trancamento de matrícula na trajetória acadêmica do universitário: condições de saída e retorno à instituição. Faculdade de Educação UNICAMP (Tese de Doutorado), 2000.

PRESTES, E. M. Da T.; FIALHO, M. G. D.; PFEIFFER, D. K. A evasáo no ensino superior globalizado e suas repercussóes na gestáo universitária. João Pessoa, 2014.

PUTNAM, Robert D. Comunidade e democracia: a experiência da Itália moderna. 5 ed. Rio de Janeiro: FGV, 2006. 257 p. ISBN 85-225-0210-2

RIBEIRO, M. A. O Projeto Profissional Familiar como Determinante da Evasáo Universitária - Um Estudo Preliminar. Revista Brasileira de Orientação Profissional, 2005, 6 (2), pp. 55-70.

SENADO FEDERAL. Senado Notícias. 2014. Disponível em: <http://www12.senado. leg.br/noticias/materias/2014/09/10/cristovam-buarque-evasao-no-ensino-superior> Acesso em: 17 jan 2015. 20:39:55

TABOSA, F. J. S.; TEIXEIRA, K. H.; SILVA, D. M. F; MADALOZZO, C. L.; MAYORGA, M. I. O. Desenvolvimento Local e Capital Social: uma Leitura sobre os núcleos e arranjos produtivos do Estado do Ceará. In: XLII Congresso Brasileiro de Economia e Sociologia Rural, 2004. Anais. Brasília: SOBER. v. 1, p. 1-14

TINTO, V. Dropout from higher education: a theoretical synthesis of recent research. Washington, Review of Educational Research v. 45, n. 1, 1975, p. 89-125. 
Classrooms as communities: exploring the education character of student

persistence. Journal de Higher Education, v. 68, no 6, Nov-Dec/ 1997, p. 599-623(25p.).

Student retention and graduation: facing the truth, living with the consequences. The Pell Institute - Occasional Paper. Washington, 2004.

TONKABONI, F.; YOUSEFY, A.; KESHTIARAY, N. Description and Recognition the Concept of Social Capital in Higher Education System. International Education Studies; Vol. 6, No. 9; 2013

VELOSO, T. C. M. A.; ALMEIDA, E. P. Evasão nos cursos de graduaçáo da Universidade Federal de Mato Grosso, campus universitário de Cuiabá: Um processo de exclusão. Cuiabá: UFMT. 2002.

WALTER, M. I. M. T.; RANINCHESKI, S.; MARINHO, D. N.; CASTRO, H. C. de O. de. Capital Social e políticas sociais no Brasil: diferenças regionais em população beneficiária de programas sociais. XI CONGRESSO BRASILEIRO DE SOCIOLOGIA, São Paulo, 2003. 